\title{
Uma nova dimensão da prática da mobilidade tecnológico- educacional: professores da Cibercultura, o que querem para suas aulas?
}

\author{
Ariana Chagas Gerzson ${ }^{1}$, Gílian Cristina Barros ${ }^{1}$, Glaucia da Silva Brito ${ }^{1}$ \\ ${ }^{1}$ Grupo de Estudos e Pesquisa Professor, Escola e Tecnologias Educacionais \\ (GEPPETE) - Universidade Federal do Paraná (UFPR) \\ CEP - 80.060-150 - Curitiba - PR - Brazil \\ ariana@hotmail.com,giliancris@gmail.com,glaucia@ufpr.br
}

\begin{abstract}
This meta-paper sustain on data from the last seven years of research of the Group of Studies and Research Teacher, School and Educational Technologies of a Federal University and listening to 291 teachers working in municipal schools in a city in the state of Santa Catarina, who were invited to answer: What would you like to be developed, treaty specified, detailed in a training course on the use of technologies to support their lessons or classes?. Responses denote that they have their desires directed learning both technical learning of technological artifacts as the joint use of these in their teaching practices. From this evidence the practice of technological-educational mobility, assumes new dimension: the mobility of instrument.

Resumo. Esse artigo pauta-se em dados dos últimos sete anos de pesquisa do Grupo de Estudos e Pesquisa Professor, Escola e Tecnologias Educacionais da Universidade Federal do Paraná e da escuta de 291 professores atuantes na rede municipal de ensino de Barra Velha no estado de Santa Catarina, que foram convidados a responder: $\mathrm{O}$ que você gostaria que fosse desenvolvido, tratado, especificado, detalhado em um curso de formação sobre o uso das tecnologias para apoio em suas aulas? As respostas denotam que os mesmos possuem seus desejos de aprendizagem direcionados tanto à aprendizagem técnica de artefatos tecnológicos quanto à articulação do uso desses em suas práticas pedagógicas. A partir dessa constatação a prática da mobilidade tecnológico-educacional, assume nova dimensão: a da mobilidade dos artefatos.
\end{abstract}

\section{O olhar quanto a "Formação Continuada": a escuta necessária às vozes dos professores}

A temática que relaciona a tríade Professor, Escola e Tecnologias na Educação, é destacada nesse artigo a partir das conclusões de pesquisa realizadas pelo Grupo de Estudos e Pesquisa: Professor, Escola e Tecnologias Educacionais (GEPPETE) da Universidade Federal do Paraná, a partir de 2007, com ênfase a análise de campo realizada em 2013, na rede pública municipal de ensino da cidade de Barra Velha, no estado de Santa Catarina, no sul do Brasil, a partir do seguinte questionamento: "O que você gostaria que fosse desenvolvido, tratado, especificado, detalhado em um curso de formação sobre o uso das tecnologias para apoio em suas aulas?’” 
Robin Morton, apresentado por [Goodson 2007] no artigo "Dar voz ao professor: as histórias de vida dos professores e seu desenvolvimento profissional", diz que:

Apoderou-se de mim a convicção de que era no cantor que a canção se tornava relevante. Analisar a canção em termos de tema, ou de estrutura rítmica, ou de variação de compasso, torna-se em minha opinião, irrelevante, se se esquecer a pessoa que nos transmite a canção. [p.67]

Ouvir quem transmite a canção, esse é um dos aspectos primados pelo GEPPETE, que parte do princípio de que para a construção de propostas de formação continuada de professores, aquelas que ocorrem em serviço, faz-se necessário "ouvir o professor" no intuito de oportunizar processos de formação que articulem teoria, prática e o contexto cultural no qual o professor habita. Contexto que revela seus desejos, necessidades e preocupações.

Para [Gatti 2008], nos últimos dez anos, cresceu geometricamente o número de iniciativas colocadas sob o grande guarda- chuva do termo "educação continuada" ou "formação continuada". Para autora, talvez não precisemos mesmo ter os limites demarcados entre os processos que se estruturam sob a descrição de "educação ou formação continuada". A mesma delega ao curso da história a responsabilidade desta definição, no entanto, como pesquisadores da área, faz-se necessário, a construção de uma consciência formal de que existe uma "vastidão de possibilidades" dentro deste rótulo.

Essa autora ainda afirma que em nosso país podemos encontrar desde cursos de graduação, especialização e capacitação profissional que outorgam diplomas certificados pelo MEC (Ministério de Educação e Cultura) e que acontecem tanto em nível médio quanto em nível superior. Cursos promovidos por setores públicos e privados, com tempos de duração os mais diversos, desde seis meses até quatro anos, presencialmente ou a distância. [Gatti 2008 p.17]

O surgimento da diversidade destes cursos, não acontece desvinculado da realidade da sociedade contemporânea. Ousa-se aqui aludir, nossa sociedade, a contextualização cultural que habitamos neste espaço-tempo, a Cibercultura.

Em [Lévy 1999], compreende-se que o ciberespaço, também chamado de rede, é um meio de comunicação que nasce da interconexão mundial dos computadores. Esse espaço reúne tanto à infraestrutura material quanto os seres humanos que navegam e o alimentam, e a "Cibercultura" é tida como o conjunto de práticas, de atitudes, de modos de pensamento, de valores e de técnicas (materiais e intelectuais), que se ampliam com o ciberespaço [p.16-17].

Corroborando com Lévy, [Lemos 2010 p. 15 e 16], afirma que a Cibercultura cria uma nova relação entre a técnica e a vida social, na qual uma verdadeira estética social cresce sob nossos olhos, alimentada pelas tecnologias do ciberespaço.

Sendo assim, entende-se que a chegada da internet às mãos dos usuários em seu ambiente de trabalho, em suas casas, nas escolas e em ambientes locados como, por exemplo, lan houses, acaba por potencializar o fenômeno cultural denominado Cibercultura. E, de tal modo, pode-se concluir que a Cibercultura é a cultura na qual 
habitamos $^{1}$, dentro e fora dos espaços escolares, se considerarmos: a infraestrutura material da comunicação que nos cerca, por meio de dispositivos fixos, como por exemplo, computadores, terminais de caixa eletrônicos e dispositivos móveis, como, celulares, smartphones, tablets, entre outros; e o que não é físico, como por exemplo, os processos de ensinar e aprender a partir de códigos e linguagens, culminando com o que Lévy chama de técnicas intelectuais, que confirmam que o tempo e o espaço atual chama-se, Cibercultura.

Outro aspecto que a Cibercultura carrega, é por exemplo, o embate que há entre o valor do que é público e privado, seja no uso de redes sociais, seja no acesso a informações de outros por hackers e crakers, seja na produção e disponibilização do conhecimento de forma livre ou proprietária. Deste modo, parte-se do pressuposto de que professores não tem como "habitar" em um espaço-tempo, denominado Cibercultura, sem estar em diálogo com os desafios e possibilidades do educar neste mesmo espaço-tempo.

E nesse contexto, o da Cibercultura, a formação de professores em um espaçotempo com uma mobilidade, plasticidade e "liquidez" tão presentes em nosso cotidiano, torna-se um desafio, ainda mais, tratando da formação continuada em serviço, àquela que ocorre quando o profissional professor já está imerso no mundo do trabalho, formação que está contida no desenvolvimento profissional desse professor.

O desenvolvimento profissional do professor abrange: o conhecimento que o professor tem de seu conteúdo, a forma como o ensina, as leituras que faz das aprendizagens dos alunos, a forma que os avalia, enfim, o exercício da prática docente, incluindo aspectos de sua carreira, agregados as formações (cursos, oficinas, especializações, congressos, palestras, entre outros) que realiza no decorrer da carreira, sendo esses, parte de sua formação, de seu desenvolvimento, logo, aspectos que definem seu desenvolvimento profissional [Marcelo Garcia 1989]. Portanto, vislumbra-se a construção de propostas de formação de professores para e com o uso de tecnologias no espaço-tempo da Cibercultura, que permitam a sobrevivência do "humano" e a articulação entre a teoria e a prática do professor.

Tem-se em [Brito e Purificação 2012 apud Moura] e em pesquisas do GEPPETE, que possuem como foco a discussão que agrega a tríade professor, escola e tecnologias na educação, a sinalização de que propostas de formação continuada de professores, que não os ouvem, nascem sob o axioma de três falhas: as de propósito, as de método e as de significação.

Como falha de propósito identifica-se o fato de que a tecnologia é apresentada como algo que simplesmente deve ser adquirido (comprado) ao invés de ser compreendido dentro de um contexto que exponha os motivos de utilizá-la no ensino, razão esta que os professores precisam conhecer, ou seja, eles necessitam refletir como computadores podem auxiliar na prática pedagógica. Como falha de método fica qualificada a circunstância de que os cursos sobre as tecnologias não deveriam limitar-se apenas a aprendizagem progressiva da informática, mas incluir o estudo das capacidades cognitivas envolvidas na construção do conhecimento com o auxílio do computador. E,

\footnotetext{
${ }^{1}$ A opção pela flexão do verbo habitar está pautada em Scherer (2005), que define habitantes como aqueles que se responsabilizam pelas suas ações e pelas dos parceiros, buscando o entendimento mútuo, a ação comunicativa, o questionamento reconstrutivo, bem como sendo parte (sentido dinâmico) do ambiente.
} 
como falha de significação nota-se a ocorrência de que em muitos cursos, promove-se apenas a capacitação para o uso de instrumentos, ferramentas ou programas, em lugar disso o que deveria ser privilegiado nestas propostas seria a construção de sentido sobre o uso de ferramentas e aplicativos nos processos educacionais, gerando assim na proposta de formação, ou no curso de forma especifica o caráter de uma "experiência cultural" e não apenas instrumental o que permitiria aos professores terem clareza quanto aos objetivos cognitivos e pedagógicos da utilização dos computadores na abordagem dos conteúdos escolares. [Brito e Purificação 2012 p.74]

Portanto, considera-se como pertinente, para determinação de um modelo de curso para formação de professores, o desejo de acolhimento de professores pautado nas preocupações e necessidades concretas dos mesmos quanto ao uso de tecnologias educacionais, dando som a suas vozes, vislumbrando a prática da mobilidade tecnológico-educacional.

\section{O delimitar do objeto: lócus, método e sujeitos no contexto da prática da mobilidade tecnológico-educacional}

Cinco dimensões da prática da mobilidade tecnológico-educacional são destacadas a partir do estudo de [Barros e Brito 2013]: a físico/espacial, a temporal, a mental (de pensamento), a dos conteúdos curriculares e a político-econômica.

A prática da mobilidade tecnológico-educacional, no trinômio professor-alunocontéudo é aquela na qual os três elementos do trinômio estão em movimento em diferentes tempos e espaços, no qual o pensamento (reorganização do pensamento) se move por meio do ensino de conteúdos curriculares, porções da cultura, que são aprendidos, potencialmente, pelo uso de dispositivos móveis ou fixos. [Barros e Brito 2013 p.9]

Ainda no estudo de [Brito e Barros 2013 p.8], que parte da formação de professores no contexto do Projeto Piloto: Um Computador por aluno no Paraná, lê-se que a dimensão político-econômica influencia diretamente as outras dimensões. Isso ocorre, pois por meio das determinações políticas e econômicas é que artefatos tecnológicos são disponibilizados para uso na escola, bem como sua manutenção, funcionamento, incluindo políticas internas e externas à escola que interferem nos usos.

Igualmente, após a análise pautada na leitura dos dados coletados na amostra deste estudo, a dos professores da rede municipal de Barra Velha, passa-se a considerar uma sexta dimensão, a mobilidade dos artefatos, como na análise que segue.

A cidade de Barra Velha, esta localizada na região sul do Brasil no estado de Santa Catarina, possui quase vinte e cinco mil habitantes, que tem seus filhos em idade escolar atendidos, em sua maioria, pela rede pública municipal de educação. Possui quinze escolas, sendo, nove de ensino fundamental (anos iniciais e finais), uma de educação especial e educação de jovens e adultos e cinco de educação infantil. A emancipação definitiva ocorreu em dezembro de 1961, pela Lei $n^{\circ} .778$, portanto, falamos de um município de cinquenta e dois anos, marcado por conflitos políticos nos últimos dez anos, mas que se desenvolveu em diversas frentes econômicas como: turismo, comércio e grandes empresas. Por ser uma cidade litorânea, passa por sazonalidade no faturamento econômico.

A rede municipal de educação de Barra Velha possuía propostas "compradas" de instituições particulares para a formação técnica no uso de tecnologias digitais, 
desvinculadas das reflexões de uso pedagógico das mesmas e das necessidades oriundas da prática docente, ou seja, da prática pedagógica dos professores, denotando assim a crise de diálogo entre aquilo que os professores desejavam e o que lhes foi oferecido como política pública de formação continuada.

Compreende-se, como prática pedagógica, aquela realizada pelo professor em sala de aula e que revela reproduções e criações que são influenciadas por aspectos econômicos, psicológicos, técnicos, culturais, éticos, políticos, afetivos e estéticos, mesmo carregando consigo a ideia de conservação. [BARROS e BRITO 2013 p.5]

E é nessa prática, a prática pedagógica que traz elementos de imobilidade, resistência e mudança é que se pautam tanto os pressupostos da formação de professores para o uso de tecnologias do GEPPETE, quanto do conceito de Prática da mobilidade tecnológico-educacional, no trinômio professor-aluno-conteúdo, conceito que vem sendo alargado e aprofundado, a partir de [Marczal e Direne 2012], [Barros et al. 2012], [Direne et al. 2012] e [Barros e Brito 2013].

A partir do inicio do ano de 2013, a rede municipal de ensino de Barra Velha, reestrutura as bases de suas propostas educacionais, essa reforma ocorre em diversas frentes, e uma delas é a que se refere ao uso pedagógico de tecnologias. E, no intuito de disparar essa reestruturação, duas das pesquisadoras do GEPPETE, a convite orientam e iniciam a discussão sobre o tema: Formação de Professores e uso de tecnologias educacionais, nessa rede de ensino.

O primeiro passo foi, presencialmente, dialogar com os professores da rede municipal de Barra Velha. Essa conversa, inicial, ocorreu por meio de uma palestra na abertura do ano letivo, que tratou do uso das tecnologias educacionais. Nesse primeiro momento, foi distribuído aos professores um questionário impresso onde um dos questionamentos era: "Você gostaria de participar de um processo de formação que tivesse como foco de reflexão sua prática pedagógica e o uso de tecnologias educacionais?", e dos cento e dezessete (117) professores que responderam o questionário, cento e nove (109) declararam que "sim", que estariam dispostos em participar de um processo de formação que tivesse como foco a prática pedagógica e o uso de tecnologias educacionais, e ainda afirmaram o interesse mesmo que este processo de formação ocorresse fora do horário de trabalho.

Também, naquele momento da palestra foi aberto um espaço de diálogo presencial onde os professores puderam expor suas dúvidas e considerações acerca do momento atual e de como podiam aprender a usar melhor os recursos das tecnologias educacionais. E pautando-se nas vozes expressas no questionário o Grupo e a Secretaria Municipal de Educação de Barra Velha, buscaram desenvolver como proposta inicial, um processo de formação denominado: "Inclusão Digital do Profissional Professor",, no qual os professores foram convidados a participar de um curso de formação instrumental, objetivando o uso de recursos digitais na vida cotidiana dos professores. O conteúdo curricular foi desenvolvido por integrantes do GEPPETE e, a certificação foi ofertada pela Secretaria de Educação da cidade.

\footnotetext{
${ }^{2} \mathrm{O}$ curso, composto por sessenta horas de formação, ofereceu informações desde como ligar e desligar um computador, bem como conceitos básicos de programas de edição de textos, salvamento de documentos, buscas na internet e recursos básicos de edição de slides.
} 
Os professores que ministraram o curso instrumental foram os profissionais responsáveis pelo uso dos laboratórios de informática nas escolas, salientando que as horas do curso, também ocorreram nesses espaços, no período noturno e nos finais de semana. Noventa e seis professores (96) inscreveram-se e cinquenta e seis (56) finalizaram o processo de formação, de sessenta horas (60h). No entanto, compreende-se que um processo de formação instrumental, não basta, até pelo número de professores que participaram desse momento de formação. Sendo assim, foi necessário um repensar, a partir dos estudos e das pesquisas que o GEPPETE vem realizando. Constatou-se que seria necessário ouvir novamente os professores e reorganizar a proposta.

Assim, de abril a setembro de 2013, decide-se apresentar questionamentos que pudessem dar indicativos sobre os reais desejos e necessidades dos professores de Barra Velha quanto ao uso de tecnologias educacionais. A pergunta, disponibilizada, por meio de formulário criado no Google Docs, foi apresentada a partir do seguinte contexto.

Constatamos que os professores do município de Barra Velha - SC, por incentivo da gestão, estão constantemente em busca de ferramentas tecnológicas diversificadas para dar suporte às suas aulas. (...). A fim de planejarmos esta formação para você e seus amigos de trabalho, responda a questão a seguir e fique a vontade para desenvolver sua resposta. Não é

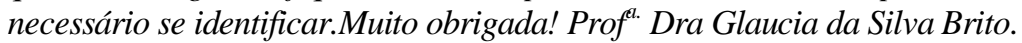

“O que você gostaria que fosse desenvolvido, tratado, especificado, detalhado em um curso de formação sobre o uso das tecnologias para apoio em suas aulas?"

Trezentos e oitenta e nove (389) professores acessaram a pergunta e duzentos e noventa e um (291) a responderam. Supõe-se que noventa e oito (98) professores, apesar de terem o acesso, por algum motivo, não se sentiram seguros o suficiente para responder o questionamento. No entanto, o alto índice de respostas, composto por $75 \%$ dos professores que acessaram, trouxeram subsídios para a análise das demandas e o retraçar de uma proposta de formação continuada que contribua para o uso de tecnologias educacionais. Na escrita dos professores, alguns termos foram repetidos constantemente, e optou-se, a partir deles estabelecer categorias para análise das demandas, e a partir das respostas organizou-se o quadro que segue.

Tabela 1: Demandas de formação apresentadas pelos professores de Barra Velha - 2013

\begin{tabular}{|l|c|c|}
\hline \multicolumn{1}{|c|}{ PALAVRAS EM REPETIÇÃo } & CATEGORIA & N. DE CITAÇÕES \\
\hline PowerPoint, Slides (ativ. p/ professores e alunos). & $\begin{array}{c}\text { Edição de Slides para e com os alunos } \\
\text { (A) }\end{array}$ & 119 \\
\hline $\begin{array}{l}\text { Sites, baixar arquivos da Internet, Pesquisa na Internet, } \\
\text { Internet, Blog. }\end{array}$ & Pesquisa na Internet (B) & 46 \\
\hline $\begin{array}{l}\text { Básico do uso do Computador, digitação, Excel, } \\
\text { formatar, funcionamento de Hardware, converter } \\
\text { arquivo, Word, tabelas, gráficos, informática. }\end{array}$ & $\begin{array}{c}\text { Apropriação de Ferramentas Básicas } \\
\text { para o uso na sua profissão (C) }\end{array}$ & 37 \\
\hline $\begin{array}{l}\text { Atividades para serem desenvolvidas em aula, } \\
\text { planejamento, softwares. }\end{array}$ & $\begin{array}{c}\text { Organização Metodológica e Didática } \\
\text { (D) }\end{array}$ & 32 \\
\hline $\begin{array}{l}\text { Filme, Movie Maker, vídeos, desenhos, exploração } \\
\text { pedagógica de imagens, fotos. }\end{array}$ & \begin{tabular}{c} 
Edição de Imagens (E) \\
\hline Atividades para Educação Infantil.
\end{tabular} & 28 \\
\hline Uso de Tablet. & Educação Infantil (F) & 14 \\
\hline
\end{tabular}


Cabe salientar que os professores questionados poderiam indicar mais de uma necessidade e dessas pinçamos as sete mais citadas, sendo assim a soma total do que desejam não apresenta o número total de respondentes, ou seja, duzentos e noventa e um (291).

Cento e dezenove (119) citações apresentaram o desejo de apropriarem-se tecnicamente do uso de editores de slides, e ainda solicitam orientações de como articular o uso destes slides com sua prática pedagógica. Já, quarenta e seis (46) professores, declararam que gostariam de aprofundar-se nas questões relativas ao uso da Internet: como navegar melhor nos websites, como baixar arquivos e realizar pesquisas. Em terceiro lugar, nas citações dos professores aparece a categoria apropriação de ferramentas básicas, onde trinta e sete (37) professores declaravam que desejavam dominar o "uso básico do Computador" melhorando sua digitação, uso de planilhas, formatação de textos, bem como, entender melhor o funcionamento do hardware, e a conversão de arquivos. E, em quarto lugar na preocupação dos professores surge a categoria organização metodológica e didática, onde trinta e dois (32) professores mencionam que querem planejar melhor as atividades desenvolvidas em sala de aula e também desejam conhecer softwares específicos para suas disciplinas. A categoria edição de imagens surge na preocupação de vinte e oito (28) professores onde os mesmos declaram desejar entender como funcionam as edições e os programas para construção de vídeo clips, bem com a edição de fotos e a possível exploração pedagógica de imagens. Quatorze professores (14) expressaram preocupação com a Educação Infantil de modo específico, declarando que gostariam de aprender atividades usando computadores que pudessem trabalhar com seus alunos entre três e seis anos de idade.

Quanto à categoria, dispositivos e aplicativos móveis, no que diz respeito ao uso de tablets, apenas seis (6) professores, ou seja, 1,6\% da amostra apresentam o desejo de se apropriarem dos recursos pedagógicos desta ferramenta tecnológica.

No entanto, ao reorganizar os dados apresentados pelos professores, em que se diferenciam os aspectos técnicos dos pedagógicos, conclui-se que a necessidade de domínio dos artefatos, das ferramentas, dos recursos apresenta-se como de interesse maior por parte dos professores dessa amostra. Vejamos.

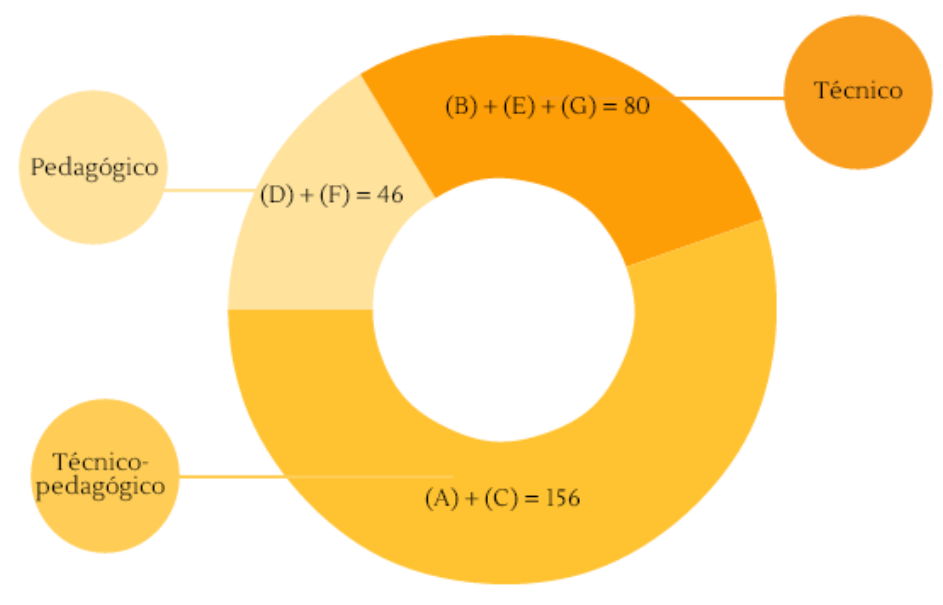

Figura 1: Demanda agrupada.

Fonte: Professores de Barra Velha - 2013

Verifica-se que, de certa forma, a elaboração do questionamento lançado, com a ênfase dada, ao uso das ferramentas (o laboratório de informática, tablet, filme, internet, etc.) em seus aspectos técnicos, pode ter induzido os respondentes a contemplarem a 
necessidade do domínio de ferramentas, artefatos em sua maioria como se lê ao agruparem-se as categorias (B), (E) e (G) de caráter essencialmente técnico, totalizando oitenta (80) citações e na interseção do agrupamento das categorias (A) e (C) que contemplam tanto aspectos técnicos e pedagógicos e totaliza cento e cinquenta e seis (156) citações.

Em outra pesquisa realizada de 2007 a 2009, por (Knoll, 2009), também em cidade do estado de Santa Catarina pode-se constatar a angústia, a ansiedade, as expectativas e os desafios que os professores pesquisados vivenciavam e, a partir dessa observação, compreender quem eram e o que sofriam os profissionais inseridos em um espaço-tempo denominado Cibercultura, que incita o do domínio desses artefatos fixos e móveis, que a compõe.

Esse aspecto se confirma pelas formas de usos expressas na pesquisa que se analisa nesse artigo, realizada em 2013, onde se destacam a necessidade e o desejo de professores em dominarem elementos de natureza essencialmente pedagógica, quando se agrupam as categorias (D) e (F) totalizando quarenta e seis (46) citações, como também técnicopedagógicos, tal que se lê na imagem anterior, na interseção das categorias (A) e (C).

A partir da conjuntura analisada, é que se fortalece a hipótese de que, os modelos de formação de professores, que deixam de ouvi-los, não têm conseguido aprofundar as reflexões e discussões pertinentes ao o que é "ser professor" na e para Cibercultura. E negar as necessidades dos professores conota em um erro estratégico, que potencializa as falhas de método, propósito e significação, já mencionadas, no sentido da formatação de propostas que não estabelecem vínculos ou conexões com as demandas culturais, pedagógicas e técnicas dos professores.

Os professores pesquisados em (Knoll, 2009) foram orientados a refletirem sobre suas necessidades concretas como professores na e para a Cibercultura. As categorias elencadas, naquele recorte, através do método de análise de conteúdo de [Bardin 2008], foram: Escola, Pesquisa, Tecnologia, Computadores e Mediação. Estas cinco categorias revelaram conceitos até então não apropriados pelos professores atuantes na rede municipal de ensino analisada naquele momento. Essas vozes ecoavam solicitando apoio, suporte para discutir, refletir e (re)avaliar suas práticas tanto num contexto técnico quanto pedagógico.

Desde a criação do GEPPETE, no ano de 2007, essas necessidades têm sido detectadas, como se verifica em [KNOLL et al., 2010], com o objetivo de discutir a tríade professor, escola e tecnologias.

A grande procura de informações e orientações na área de educação, formação de professores, escola e tecnologias educacionais, fez com que a professora responsável pela disciplina que aborda o referido tema na UFPR, no Programa de Pós-graduação em Educação, na linha Cultura, Escola e Ensino organizasse e estruturasse a formação do GEPPETE. Este movimento vem crescendo nos últimos sete anos, e as conclusões das pesquisas realizadas no Grupo apontam à necessidade de que o professor "seja ouvido" na e para constituição de Políticas Públicas de Formação de Professores para o uso de Tecnologias Educacionais. Caso contrário, entende-se que há um risco eminente na estruturação de Políticas Públicas de Formação Continuada de Professores, totalmente desvinculadas da realidade cultural desses, o que já seria por si só, a partir de nossa hipótese, premissa básica para o insucesso dessas ações de formação. 
Também nesse contexto, o de preparar professores para habitarem a Cibercultura, o conceito de Prática da mobilidade tecnológico-educacional, se amplia, a partir da necessidade de domínio dos artefatos por parte dos professores e a (re)organização de seus usos em suas práticas pedagógicas, passando a contar com seis dimensões em movimento e que se articulam entre si: a físico/espacial, a temporal, a mental (de pensamento), a dos conteúdos curriculares, a político-econômica e a dos artefatos.

\section{Conclusões iniciais}

Da análise feita até aqui, questiona-se: Será que professores e alunos estão conectados realmente, concretamente no espaço-tempo da Cibercultura, da Cultura da Mobilidade de [Lemos 2009]? Estariam "todos" conectados, num espaço-tempo no qual, dispositivos móveis, como celulares, tablets e smartphones estão presentes na maioria dos lares, conforme ouvimos em muitos noticiários? Por que professores ainda sentem a necessidade de dominarem recursos como editores de texto e apresentação como os da amostra que analisamos? Por que apenas 1,6\% apresentaram o desejo de aquisição de conhecimentos relativos ao uso de dispositivos móveis, como tablets? Seriam as mobilidades constrangidas que causam imobilidades [Lemos 2009]? Ou porque os mesmos ainda não dispõem de tais dispositivos na escola?

Não estamos com estes questionamentos afirmando que não defendemos o uso de aplicativos móveis, ao contrário, o Grupo defende antes de tudo a inclusão digital do profissional professor, no entanto, defendemos que antes de estruturarem-se propostas de inclusão digital ou de formação continuada para esses profissionais que se pergunte o que desejam, para que não se corra o risco de inundarmos as escolas com "tecnologias físicas" como máquinas, dispositivos e aplicativos móveis, com recursos públicos sem esse seja efetivamente "o desejo" dos professores.

Faz-se primordial a escuta sistemática e profunda do professor para a construção de propostas que sejam formatadas não sob a ótica míope de articulação de receitas tecnologizadas e instrumentais de formação, porém a partir das necessidades concretas de professores, alunos e escolas na busca de um caminho para educar na e para a Cibercultura, espaço-tempo no qual habitamos.

Enfim, buscou-se orientar a equipe da Secretaria de Educação do Município de Barra Velha no sentido de que possam estruturar, para os próximos anos, uma proposta de formação continuada que busque reorganizar as demandas apresentadas pelos professores com relação ao uso das tecnologias educacionais. Almejamos que outras redes de educação, públicas ou não, façam leitura crítica de seus processos de formação de professores e impetrem de forma individual e, preferencialmente, coletiva, a organização de propostas de formação que acatem e façam ecoar as vozes dos professores.

\section{Referências}

Barros, G.C.; Direne, A.; Kutzke, A. R. e Silva, W. da.. (2012) “A mobilidade tecnológicoeducacional e as possibilidades de coincidência entre tecnologias e currículo por meio da produção e uso de webquests". In: III Seminário Web Currículo - Educação e Mobilidade, São Paulo: PUCSP. goo.g1/h7Nox2. Agosto.

Barros, G. C.; Brito, G. da S. "Prática da mobilidade tecnológico-educacional, um ensaio sobre a definição do conceito". In: Anais do Simpósio Brasileiro de Informática na 
Educação. 2013. http://www.br-ie.org/pub/index.php/sbie/article/view/2485/2144. Agosto.

Bardin, L. “Análise de conteúdo”. Lisboa: Edições 70, 2008.

Direne, A.; Kutzke A; Marczal, D., Barros, G.; Bazzo, G.; Silva, F.; Silva, W. da; Peres, L. and Moura, L. (2012) “Aprofundamento da mobilidade tecnológico-educacional por meio de jogos intelectivos como facilitadores da comunicação professor-aluno em redes virtuais de ensino." In: SBC. I Workshop de Desafios da Computação Aplicada a Educação. http://www.lbd.dcc.ufmg.br/bdbcomp/servlet/Trabalho?id=11450. Agosto.

Gatti, B. A. "Análise das políticas públicas para formação continuada no Brasil, na última década." Educ. v13 n.37. Rio de Janeiro. Jan/abr. 2008

Goodson, I. F. Dar voz ao professor: as histórias de vida dos professores e o seu desenvolvimento profissional. In: Nóvoa, A. (Org.) "Vidas de professores." Lisboa: Porto, p.63-78, 1995.

Brito, G. S.; Purificação, I. "Educação e novas tecnologias: um re-pensar - $3^{\text {a }}$ Edição. 3. ed. Curitiba-PR: Editora IBPEX Dialógica, 2012. 143p .

Knoll, A. C. G.; Brito, G. da S.; Simonian, M. "Grupos de pesquisa: o acolhimento aos habitantes, visitantes e transeuntes de um ambiente virtual." Revista Diálogo Educacional, v. 10 , n. 31 , p. 505-520, 2010.

Knoll, A. C. G. “Tecnologia e educação: vamos ouvir o professor?” Dissertação de Mestrado em Educação. Orientação Gláucia da Silva Brito. PPGE- UFPR 2009.

Lemos, A. "Cibercultura, tecnologia e vida social na cultura contemporânea." Porto Alegre: Sulinas, 2010.

"Cultura da mobilidade." Revista FAMECOS. Porto Alegre n. 40 dezembro. http://revistaseletronicas.pucrs.br/ojs/index.php/revistafamecos/article/viewFile/6314/4589 . 2009. Agosto

Lévy, P. “Cibercultura”.Trad. Carlos Irineu da Costa. São Paulo: Editora 34, 1999.

Marcelo Garcia, C. "Formação de professores: para uma mudança educativa." Porto, PT: Porto Editora, 1989. p.17 a 68.

Marczal, D. e Direne, A. (2012) "FARMA: Uma ferramenta de autoria para objetos de aprendizagem de conceitos matemáticos." Anais do $23^{\circ}$ Simpósio Brasileiro de Informática na Educação (SBIE 2012), ISSN 2316-6533 Rio de Janeiro, 26-30 de Novembro. http://www.lbd.dcc.ufmg.br/colecoes/sbie/2012/0028.pdf. Agosto.

Scherer, S. "Uma estética possível para a educação bimodal: aprendizagem e comunicação em ambientes presenciais e virtuais. Uma experiência em estatística aplicada à educação." São Paulo, 2005. 241 f. Tese (Doutorado em Educação) - Pontifícia Universidade Católica de São Paulo, São Paulo, 2005. 